American Journal of Biostatistics 1 (1): 17-22, 2010

ISSN 1948-9889

C 2010 Science Publications

\title{
Measure for No Three-Factor Interaction Model in Three-Way Contingency Tables
}

\author{
Kouji Yamamoto, Kyoji Hori and Sadao Tomizawa \\ Department of Information Sciences, Faculty of Science and Technology, \\ Tokyo University of Science, Noda City, Chiba, 278-8510, Japan
}

\begin{abstract}
Problem statement: For $2 \times 2 \times \mathrm{K}$ contingency tables, the measure is considered to represent the degree of departure from a log-linear model of No Three-Factor Interaction (NOTFI). We are interested in considering a similar measure for general $\mathrm{I} \times \mathrm{J} \times \mathrm{K}$ contingency tables. Approach: The present study proposed a measure to represent the degree of departure from the NOTFI model for $\mathrm{I} \times \mathrm{J} \times \mathrm{K}$ contingency tables. Also the approximate confidence interval for the proposed measure is given. Results: The proposed measure was applied and analyzed (1) for a $3 \times 4 \times 4$ cross-classification data of dumping severity, hospital and operation which treat duodenal ulcer patients corresponding to removal of various amounts of the stomach and (2) for a $2 \times 3 \times 4$ cross-classification data of experiment of animals (mouse and rat) on cancer (the tumor of leukemia and lymphoma) and tolazamide. Conclusion: The proposed measure is useful for comparing the degrees of departure from the NOTFI model in several tables.
\end{abstract}

Key words: Diversity index, odds-ratio, power-divergence

\section{INTRODUCTION}

For an $\mathrm{I} \times \mathrm{J} \times \mathrm{K}$ contingency table, let $\mathrm{p}_{\mathrm{ijk}}$ denote the probability that an observation will fall in the $(\mathrm{i}, \mathrm{j}, \mathrm{k})$ th cell of the table $(i=1, \ldots, I ; j=1, \ldots, J ; k=1, \ldots, K)$. One can express $\log \mathrm{p}_{\mathrm{ijk}}$ as:

$$
\begin{aligned}
\log \mathrm{p}_{\mathrm{ijk}}= & \mathrm{u}+\mathrm{u}_{1(\mathrm{i})}+\mathrm{u}_{2(\mathrm{j})}+\mathrm{u}_{3(\mathrm{k})} \\
& +\mathrm{u}_{12(\mathrm{ij})}+\mathrm{u}_{13(\mathrm{ik})}+\mathrm{u}_{23(\mathrm{jk})}+\mathrm{u}_{123(\mathrm{j} \mathrm{jk})}
\end{aligned}
$$

Where:

$$
\begin{gathered}
\sum_{\mathrm{i}} \mathrm{u}_{\mathrm{s}(\mathrm{i})}=0 \quad(\mathrm{~s}=1,2,3) \\
\sum_{\mathrm{i}} \mathrm{u}_{\mathrm{st}(\mathrm{ij})}=\sum_{\mathrm{j}} \mathrm{u}_{\mathrm{st}(\mathrm{ij})}=0 \quad(1 \leq \mathrm{s}<\mathrm{t} \leq 3) \\
\sum_{\mathrm{i}} \mathrm{u}_{123(\mathrm{ijk})}=\sum_{\mathrm{j}} \mathrm{u}_{123(\mathrm{ijk})}=\sum_{\mathrm{k}} \mathrm{u}_{123(\mathrm{ijk})}=0
\end{gathered}
$$

e.g., Bishop et al. (1975). Then the No Three-Factor Interaction (NOTFI) model is defined by setting the parameters as:

$$
\mathrm{u}_{123(\mathrm{ijk})}=0
$$

for all $\mathrm{i}, \mathrm{j}, \mathrm{k}$. This model can also be expressed as:

$$
\begin{aligned}
& \theta_{\mathrm{ij}(1)}=\cdots=\theta_{\mathrm{ij}(\mathrm{K})} \\
& \quad(\mathrm{i}=1, \ldots, \mathrm{I}-1 ; \mathrm{j}=1, \ldots, \mathrm{J}-1)
\end{aligned}
$$

Where:

$$
\theta_{i j(t)}=\frac{p_{i j t} p_{i+1, j+1, t}}{p_{i, j+1, t} p_{i+1, j, t}}
$$

e.g., Agresti (1984). When the NOTFI model does not hold, we are interested in measuring the degree of departure from the NOTFI model, i.e., the degree of non-uniformity of odds-ratios $\left\{\theta_{\mathrm{ij}(\mathrm{t})}\right\}$.

For the $2 \times 2 \times \mathrm{K}$ contingency table, namely, when $\mathrm{I}=\mathrm{J}=2$, Tomizawa (1993) and Yamamoto et al. (2008) considered measures which represent the degree of departure from the NOTFI model.

The purpose of present research is to extend these measures into the $\mathrm{I} \times \mathrm{J} \times \mathrm{K}$ table. The extended measure

Corresponding Author: Kouji Yamamoto, Department of Information Sciences, Faculty of Science and Technology, Tokyo University of Science, Noda City, Chiba, 278-8510, Japan 
would be useful for comparing the degrees of departure from the NOTFI model in several tables.

\section{MATERIALS AND METHODS}

An extended measure: Consider the $\mathrm{I} \times \mathrm{J} \times \mathrm{K}$ contingency table. Let:

$$
\begin{aligned}
& \mathrm{D}_{\mathrm{ij}}=\sum_{\mathrm{k}=1}^{\mathrm{K}} \theta_{\mathrm{ij}(\mathrm{k})}, \quad \theta_{\mathrm{ij}(\mathrm{t})}^{*}=\frac{\theta_{\mathrm{ij}(\mathrm{t})}}{\mathrm{D}_{\mathrm{ij}}} \\
& (\mathrm{i}=1, \ldots, \mathrm{I}-1 ; \mathrm{j}=1, \ldots, \mathrm{J}-1 ; \mathrm{t}=1, \ldots, \mathrm{K})
\end{aligned}
$$

Assuming that the $\left\{p_{\mathrm{ijk}}\right\}$ are positive, consider a measure to represent the degree of departure from the NOTFI model, defined by:

$$
\Psi^{(\lambda)}=\frac{1}{\delta^{*}} \sum_{\mathrm{i}=1}^{\mathrm{I}-1} \sum_{\mathrm{j}=1}^{\mathrm{J}-1} \delta_{\mathrm{ij}} \varphi_{\mathrm{ij}}^{(\lambda)} \quad(\lambda>-1)
$$

Where:

$$
\begin{gathered}
\delta_{\mathrm{ij}}=\sum_{\mathrm{l}=\mathrm{i}}^{\mathrm{i}+1} \sum_{\mathrm{m}=\mathrm{j}}^{\mathrm{j}+1} \sum_{\mathrm{n}=1}^{\mathrm{K}} \mathrm{p}_{\mathrm{Imn}} \\
\delta^{*}=\sum_{\mathrm{s}=1}^{\mathrm{I}-1} \sum_{\mathrm{t}=1}^{\mathrm{J}-1} \delta_{\mathrm{st}} \\
\varphi_{\mathrm{ij}}^{(\lambda)}=1-\frac{\mathrm{H}_{\mathrm{ij}}^{(\lambda)}\left(\theta^{*}\right)}{\mathrm{C}^{(\lambda)}} \\
\mathrm{H}_{\mathrm{ij}}^{(\lambda)}\left(\theta^{*}\right)=\frac{1}{\lambda}\left(1-\sum_{\mathrm{t}=1}^{\mathrm{K}}\left(\theta_{\mathrm{ij}(\mathrm{t})}^{*}\right)^{\lambda+1}\right) \\
\mathrm{C}^{(\lambda)}=\frac{1}{\lambda}\left[1-\left(\frac{1}{\mathrm{~K}}\right)^{\lambda}\right]
\end{gathered}
$$

and the value at $\lambda=0$ is taken to be the limit as $\lambda \rightarrow 0$. Note that $\lambda$ is a real value that is chosen by the user. The submeasure $\varphi_{i j}^{(\lambda)}$ represents the degree of nonuniformity of odds-ratios $\left\{\theta_{\mathrm{ij}(\mathrm{t} t)}\right\}$ for fixed $\mathrm{i}$ and $\mathrm{j}$. Note that $\mathrm{H}_{\mathrm{ij}}^{(\lambda)}\left(\theta^{*}\right)$ is Patil and Taillie (1982) diversity index of degree $\lambda$ for $\left\{\theta_{\mathrm{ij}(\mathrm{t})}^{*}\right\}, \mathrm{t}=1, \ldots, \mathrm{K}$, which includes the Shannon entropy (when $\lambda=0$ ) in a special case. When $\mathrm{I}=\mathrm{J}=2$, the measure $\Psi^{(\lambda)}$ is identical with the measure in Yamamoto et al. (2008) and when $\mathrm{I}=\mathrm{J}=2$ and $\lambda=0$, it is identical with the measure in Tomizawa (1993). The submeasure $\varphi_{i j}^{(\lambda)}$ may be expressed as:

$$
\varphi_{i j}^{(\lambda)}=\frac{\lambda+1}{K^{\lambda} C^{(\lambda)}} I_{i j}^{(\lambda)}\left(\left\{\theta_{i j(t)}^{*}\right\} ;\left\{\frac{1}{K}\right\}\right)
$$

Where:

$$
\mathrm{I}_{\mathrm{ij}}^{(\lambda)}(\cdot ;)=\frac{1}{\lambda(\lambda+1)} \sum_{\mathrm{t}=1}^{\mathrm{K}} \theta_{\mathrm{ij}(\mathrm{t})}^{*}\left[\left(\frac{\theta_{\mathrm{ij}(\mathrm{t})}^{*}}{1 / \mathrm{K}}\right)^{\lambda}-1\right]
$$

Note that $I_{\mathrm{ij}}^{(\lambda)}\left(\left\{\theta_{\mathrm{ij}(t)}^{*}\right\} ;\left\{\frac{1}{\mathrm{~K}}\right\}\right)$ is the power-divergence between $\left\{\theta_{\mathrm{ij}(\mathrm{t})}^{*}\right\}$ and $\left\{\frac{1}{\mathrm{~K}}\right\}$, which includes the KullbackLeibler information (when $\lambda=0$ ) in a special case. For more details of the power-divergence, Cressie and Read (1984) and Read and Cressie (1988).

The $\mathrm{H}_{\mathrm{ij}}^{(\lambda)}\left(\theta^{*}\right)$ must lie between 0 and $\mathrm{C}^{(\lambda)}$ but it cannot attain the lower limit of 0 in terms of the assumption that are $\left\{\mathrm{p}_{\mathrm{ijk}}\right\}$ positive. Thus the submeasure $\varphi_{i j}^{(\lambda)}$ must lie between 0 and 1 and therefore the measure $\Psi^{(\lambda)}$ must lie between 0 and 1 , but it cannot attain the upper limit of 1 . Now it is easily seen that for each $\lambda(>-1)$, the NOTFI model holds if and only if the $\varphi_{i j}^{(\lambda)}=0$ for every $\mathrm{i}=1, \ldots, \mathrm{I}-1 ; \mathrm{j}=1, \ldots, \mathrm{J}-1$, i.e., $\Psi^{(\lambda)}=0$. According to the weighted sum of the diversity index or the power-divergence, $\Psi^{(\lambda)}$ represents the degree of departure from NOTFI model and the degree increases as the value of $\Psi^{(\lambda)}$ increases.

Approximate confidence interval for measure: Let $\mathrm{n}_{\mathrm{ijk}}$ denote the observed frequency in the $(\mathrm{i}, \mathrm{j}, \mathrm{k})$ th cell of the $\mathrm{I} \times \mathrm{J} \times \mathrm{K}$ table $(\mathrm{i}=1, \ldots, \mathrm{I} ; \mathrm{j}=1, \ldots, \mathrm{J} ; \mathrm{k}=1, \ldots, \mathrm{K})$. Assuming that $\left\{n_{\mathrm{ijk}}\right\}$ result from full multinomial sampling, we shall consider an approximate standard error and large-sample confidence interval of the measure $\Psi^{(\lambda)}$, using the delta method of which descriptions are given by, for example, Bishop et al. (1975). The sample version of measure $\Psi^{(\lambda)}$, i.e., $\hat{\Psi}^{(\lambda)}$, is given by $\Psi^{(\lambda)}$ with $\left\{\mathrm{p}_{\mathrm{ijk}}\right\}$ replaced by $\left\{\hat{\mathrm{p}}_{\mathrm{ijk}}\right\}$, where $\hat{\mathrm{p}}_{\mathrm{ijk}}=\mathrm{n}_{\mathrm{ijk}} / \mathrm{n}$ and $\mathrm{n}=\sum \sum \sum \mathrm{n}_{\mathrm{ijk}}$. Using the delta method, $\sqrt{\mathrm{n}}\left(\hat{\Psi}^{(\lambda)}-\Psi^{(\lambda)}\right)$ has asymptotically $($ as $\mathrm{n} \rightarrow \infty)$ a normal distribution with mean zero and variance:

$$
\sigma^{2}=\frac{1}{\left(\delta^{*}\right)^{2}} \times\left[\sum_{k=1}^{1} \sum_{l=1}^{J} \sum_{m=1}^{K}\left(w_{k l m}^{(\lambda)}\right)^{2} p_{k l m}-\left(\sum_{k=1}^{1} \sum_{k=1}^{J} \sum_{m=1}^{K} w_{k l m}^{(\lambda)} p_{k l m}\right)^{2}\right]
$$

with:

$$
\begin{aligned}
\mathrm{w}_{\mathrm{klm}}^{(\lambda)}= & \varphi_{\mathrm{k}-1,1-1}^{(\lambda)}+\varphi_{\mathrm{k}-1,1}^{(\lambda)}+\varphi_{\mathrm{k}, 1-1}^{(\lambda)}+\varphi_{\mathrm{kl}}^{(\lambda)}-\Delta_{\mathrm{kl}} \Psi^{(\lambda)} \\
& +\frac{1}{\mathrm{p}_{\mathrm{klm}}}\left(\mathrm{A}_{\mathrm{k}-1,1-1(\mathrm{~m})}^{(\lambda)}-\mathrm{A}_{\mathrm{k}-1,1 \mathrm{~m})}^{(\lambda)}-\mathrm{A}_{\mathrm{k}, \mathrm{l}-1(\mathrm{~m})}^{(\lambda)}+\mathrm{A}_{\mathrm{kl}(\mathrm{m})}^{(\lambda)}\right)
\end{aligned}
$$




$$
\begin{gathered}
\mathrm{A}_{\mathrm{st}(\mathrm{m})}^{(\lambda)}=\frac{(\lambda+1) \delta_{\mathrm{st}} \theta_{\mathrm{st}(\mathrm{m})}}{\lambda \mathrm{C}^{(\lambda)} \mathrm{D}_{\mathrm{st}}^{\lambda+2} \times} \\
{\left[\mathrm{D}_{\mathrm{st}}\left(\theta_{\mathrm{st}(\mathrm{m})}\right)^{\lambda}-\sum_{\mathrm{u}=1}^{\mathrm{K}}\left(\theta_{\mathrm{st}(\mathrm{u})}\right)^{\lambda+1}\right]} \\
\varphi_{\mathrm{s} 0}^{(\lambda)}=\varphi_{\mathrm{sJ}}^{(\lambda)}=\varphi_{0 \mathrm{t}}^{(\lambda)}=\varphi_{\mathrm{It}}^{(\lambda)}=0 \\
\mathrm{~A}_{\mathrm{s} 0(\mathrm{~m})}^{(\lambda)}=\mathrm{A}_{\mathrm{sJ}(\mathrm{m})}^{(\lambda)}=\mathrm{A}_{0 \mathrm{t}(\mathrm{m})}^{(\lambda)}=\mathrm{A}_{\mathrm{It}(\mathrm{m})}^{(\lambda)}=0 \\
(\mathrm{~s}=0,1, \ldots, \mathrm{I} ; \mathrm{t}=0,1, \ldots, \mathrm{J}) \\
\Delta_{\mathrm{st}}= \begin{cases}(\mathrm{s}=1 ; \mathrm{t}=1), \\
1 \\
1 & (\mathrm{~s}=1 ; \mathrm{t}=\mathrm{J}), \\
1 & (\mathrm{~s}=\mathrm{I} ; \mathrm{t}=1), \\
2 & (\mathrm{~s}=1, \mathrm{I} ; \mathrm{t}=2, \ldots, \mathrm{J}-1), \\
2 & (\mathrm{~s}=2, \ldots, \mathrm{I}-1 ; \mathrm{t}=1, \mathrm{~J}), \\
4 & (\mathrm{~s}=2, \ldots, \mathrm{I}-1 ; \mathrm{t}=2, \ldots, \mathrm{J}-1)\end{cases}
\end{gathered}
$$

Let $\hat{\sigma}^{2}$ denote $\sigma^{2}$ with $\left\{\mathrm{p}_{\mathrm{ijk}}\right\}$ replaced by $\left\{\hat{\mathrm{p}}_{\mathrm{ijk}}\right\}$. Then $\hat{\sigma} / \sqrt{\mathrm{n}}$ is an estimated approximate standard error for $\hat{\Psi}^{(\lambda)}$ and $\hat{\Psi}^{(\lambda)} \pm z_{\mathrm{p} / 2} \hat{\sigma} / \sqrt{\mathrm{n}}$ is an approximate $100(1-p)$ percent confidence interval for $\Psi^{(\lambda)}$, where $\mathrm{z}_{\mathrm{p} / 2}$ is the percentage point from the standard normal distribution corresponding to a two-tail probability equal to $\mathrm{p}$.

\section{RESULTS}

Example 1: The data in Table 1a, taken from Grizzle et al. (1969), are a $3 \times 4 \times 4$ cross-classification of dumping severity, hospital and operation (Agresti, 1984; Tomizawa, 1992). Also, Table 1b rearranges the data in Table 1a. Four different operations for treating duodenal ulcer patients correspond to removal of various amounts of the stomach. Operation $\mathrm{A}$ is drainage and vagotomy, $\mathrm{B}$ is $25 \%$ resection (antrectomy) and vagotomy, $\mathrm{C}$ is 50\% resection (hemigastrectomy) and vagotomy and $\mathrm{D}$ is $75 \%$ resection. The dumping severity variable describes the extent of an undesirable potential consequence of the operation.

The NOTFI model indicates (1) the odds ratios (association) between the dumping severity and hospital are uniform among the operations and (2) the odds ratios (association) between the dumping severity and operation are uniform among the hospitals. For these data, we are now interested in two kinds of the degrees of departure from the NOTFI model; namely, (1) what degree the odds ratios (association) between the dumping severity and hospital are apart from the uniformity among the operations and (2) what degree the odds ratios (association) between the dumping severity and operation are apart from the uniformity among the hospitals.

We see from Table 2 that the estimated value of measure $\Psi^{(\lambda)}$ for (1) is different (though it is slight) from that for (2). In addition, we see that the degree of departure from the uniformity of odds ratios between the dumping severity and hospital among the operations is somewhat greater than the degree of departure from the uniformity of odds ratios between the dumping severity and operation among the hospitals.

Example 2: The data in Table 3, taken from Yanagawa (1986), are $2 \times 3 \times 4$ cross-classification of experiment on animal for cancer according to the tolazamide (control, lower dose and higher dose), the tumor of leukemia and

\begin{tabular}{|c|c|c|c|c|c|}
\hline \multirow[b]{2}{*}{ Operation } & \multirow{2}{*}{$\begin{array}{l}\text { Dumping } \\
\text { severity }\end{array}$} & \multicolumn{4}{|c|}{ Hospital } \\
\hline & & 1 & 2 & 3 & 4 \\
\hline \multicolumn{6}{|c|}{ (a) Observations } \\
\hline \multirow[t]{3}{*}{ A } & $\mathrm{N}$ & 23 & 18 & 8 & 12 \\
\hline & S & 7 & 6 & 6 & 9 \\
\hline & M & 2 & 1 & 3 & 1 \\
\hline \multirow[t]{3}{*}{ B } & $\mathrm{N}$ & 23 & 18 & 12 & 15 \\
\hline & S & 10 & 6 & 4 & 3 \\
\hline & M & 5 & 2 & 4 & 2 \\
\hline \multirow[t]{3}{*}{$\mathrm{C}$} & $\mathrm{N}$ & 20 & 13 & 11 & 14 \\
\hline & $\mathrm{S}$ & 13 & 13 & 6 & 8 \\
\hline & M & 5 & 2 & 2 & 3 \\
\hline \multirow[t]{4}{*}{$\mathrm{D}$} & $\mathrm{N}$ & 24 & 9 & 7 & 13 \\
\hline & S & 10 & 15 & 7 & 6 \\
\hline & M & 6 & 2 & 4 & 4 \\
\hline & & \multicolumn{4}{|c|}{ Operation } \\
\hline Hospital & & A & $\mathrm{B}$ & $\mathrm{C}$ & $\mathrm{D}$ \\
\hline \multicolumn{6}{|c|}{ (b) Table rearranged Table $1 \mathrm{a}$} \\
\hline \multirow[t]{3}{*}{1} & $\mathrm{~N}$ & 23 & 23 & 20 & 24 \\
\hline & $\mathrm{S}$ & 7 & 10 & 13 & 10 \\
\hline & M & 2 & 5 & 5 & 6 \\
\hline \multirow[t]{3}{*}{2} & $\mathrm{~N}$ & 18 & 18 & 13 & 9 \\
\hline & S & 6 & 6 & 13 & 15 \\
\hline & M & 1 & 2 & 2 & 2 \\
\hline \multirow[t]{3}{*}{3} & $\mathrm{~N}$ & 8 & 12 & 11 & 7 \\
\hline & S & 6 & 4 & 6 & 7 \\
\hline & M & 3 & 4 & 2 & 4 \\
\hline \multirow[t]{3}{*}{4} & $\mathrm{~N}$ & 12 & 15 & 14 & 13 \\
\hline & S & 9 & 3 & 8 & 6 \\
\hline & $\mathrm{M}$ & 1 & 2 & 3 & 4 \\
\hline
\end{tabular}
lymphoma and the animals (female mouse, male mouse, female rat and male rat).

Table 1: Cross-classification of duodenal ulcer patients according to dumping severity, hospital and operation; taken from Grizzle et al. (1969)

Note: N: None; S: Slight; M: Moderate 
Am. J. Biostatistics 1 (1): 17-22, 2010

Table 2: Estimates of $\Psi^{(\lambda)}$, estimated approximate standard error for $\hat{\Psi}^{(\lambda)}$, approximate $95 \%$ confidence interval for $\Psi^{(\lambda)}$, applied to Table 1a and 1b

\begin{tabular}{llll}
\hline Values of $\lambda$ & $\begin{array}{l}\text { Estimated } \\
\text { measure }\end{array}$ & $\begin{array}{l}\text { Standard } \\
\text { error }\end{array}$ & $\begin{array}{l}\text { Confidence } \\
\text { interval }\end{array}$ \\
\hline \multicolumn{2}{l}{ (a) For Table 1a } \\
-0.4 & 0.074 & 0.051 & $(-0.026,0.174)$ \\
0 & 0.095 & 0.066 & $(-0.034,0.223)$ \\
0.6 & 0.100 & 0.072 & $(-0.041,0.241)$ \\
1.0 & 0.093 & 0.070 & $(-0.044,0.231)$ \\
1.6 & 0.077 & 0.063 & $(-0.046,0.200)$ \\
(b) For Table 1b & & \\
-0.4 & 0.054 & 0.042 & $(-0.029,0.136)$ \\
0 & 0.067 & 0.053 & $(-0.037,0.171)$ \\
0.6 & 0.068 & 0.056 & $(-0.041,0.178)$ \\
1.0 & 0.062 & 0.053 & $(-0.041,0.165)$ \\
1.6 & 0.048 & 0.045 & $(-0.039,0.136)$ \\
\hline
\end{tabular}

Table 3: Cross-classification of experiment on animal for cancer according to tolazamide, tumor and animal; taken from Yanagawa (1986)

\begin{tabular}{llccc}
\hline \multicolumn{5}{c}{ Tolazamide } \\
\cline { 3 - 4 } Animal & Tumor & Control & Lower dose & Higher dose \\
\hline Female & No & 9 & 31 & 30 \\
Mouse & Yes & 6 & 2 & 4 \\
Male & No & 10 & 30 & 33 \\
Mouse & Yes & 4 & 5 & 1 \\
Female & No & 11 & 30 & 33 \\
Rat & Yes & 4 & 3 & 2 \\
Male & No & 13 & 34 & 31 \\
Rat & Yes & 2 & 1 & 4 \\
\hline
\end{tabular}

Table 4: Estimates of $\Psi^{(\lambda)}$, estimated approximate standard error for $\hat{\Psi}^{(\lambda)}$, approximate $95 \%$ confidence interval for $\Psi^{(\lambda)}$, applied to Table 3

\begin{tabular}{llll}
\hline Values of $\lambda$ & $\begin{array}{l}\text { Estimated } \\
\text { measure }\end{array}$ & $\begin{array}{l}\text { Standard } \\
\text { error }\end{array}$ & $\begin{array}{l}\text { Confidence } \\
\text { interval }\end{array}$ \\
\hline-0.4 & 0.182 & 0.141 & $(-0.095,0.459)$ \\
0 & 0.215 & 0.175 & $(-0.128,0.558)$ \\
0.6 & 0.211 & 0.199 & $(-0.179,0.601)$ \\
1.0 & 0.192 & 0.205 & $(-0.209,0.594)$ \\
1.6 & 0.158 & 0.202 & $(-0.239,0.554)$ \\
\hline
\end{tabular}

The NOTFI model indicates that the odds ratios (association) between the dose of tolazamide and the tumor are uniform among the animals. For these data, we are now interested in the degree of departure from the NOTFI model; namely what degree the odds ratios (association) between the dose of tolazamide and the tumor are apart from the uniformity among the animals.

Table 4 shows the degree of departure from the uniformity of odds ratios between the dose of tolazamide and the tumor among the four kinds of animals. We see from Table 2 and 4 that the degree of departure from the NOTFI model is greater for the data in Table 3 than for the data in Table 1.
Table 5: Values of power-divergence statistic $\mathrm{W}^{(\lambda)}$ for testing goodness-of-fit of the NOTFI model applied to Table 1a, $1 \mathrm{~b}$ and 3

\begin{tabular}{lcl}
\hline Values of $\lambda$ & For Table 1a & For Table 1b \\
\hline (a) For Table 1a and 1b with 18 degrees of freedom & \\
-0.4 & 12.50 & 12.50 \\
0 & 12.50 & 12.50 \\
0.6 & 12.56 & 12.56 \\
1.0 & 12.64 & 12.64 \\
1.6 & 12.82 & 12.82 \\
\hline Values of $\lambda$ & For Table 3 \\
\hline (b) For Table 3 with 6 degrees of freedom & \\
-0.4 & 7.473 \\
0 & & 7.322 \\
0.6 & 7.264 \\
1.0 & 7.331 \\
1.6 & 7.589 \\
\hline
\end{tabular}

\section{DISCUSSION}

The readers may be interested in the relation between the measure and the test statistic for goodnessof-fit of the NOTFI model. Let $\mathrm{W}^{(\lambda)}$ denote the powerdivergence statistic for testing goodness-of-fit of the NOTFI model with (I-1)(J-1)(K-1) degrees of freedom, i.e.:

$$
\begin{array}{r}
\mathrm{W}^{(\lambda)}=\frac{2}{\lambda(\lambda+1)} \sum_{\mathrm{i}=1}^{\mathrm{I}} \sum_{\mathrm{j}=1}^{\mathrm{J}} \sum_{\mathrm{k}=1}^{\mathrm{K}} \mathrm{n}_{\mathrm{ijk}}\left[\left(\frac{\mathrm{n}_{\mathrm{ijk}}}{\hat{\mathrm{m}}_{\mathrm{ijk}}}\right)^{\lambda}-1\right] \\
(-\infty<\lambda<\infty)
\end{array}
$$

where $\hat{\mathrm{m}}_{\mathrm{ijk}}$ is the maximum likelihood estimate of the expected frequency $\mathrm{m}_{\mathrm{ijk}}$ under the NOTFI model and the values at $\lambda=-1$ and $\lambda=0$ are taken to be the limits as $\lambda \rightarrow-1$ and $\lambda \rightarrow 0$, respectively

For the details of power-divergence test statistic, Cressie and Read (1984) and Read and Cressie (1988). In particular, note that $\mathrm{W}^{(0)}$ and $\mathrm{W}^{(1)}$ are the likelihood ratio and Pearson chi-squared statistics, respectively. Table 5 gives the values of $\mathrm{W}^{(\lambda)}$ applied to the data in Tables $1 \mathrm{a}, 1 \mathrm{~b}$ and 3 . We point out that the value of $\mathrm{W}^{(\lambda)}$ for Table $1 \mathrm{a}$ is theoretically equal to that for Table $1 \mathrm{~b}$ though the value of $\hat{\Psi}^{(\lambda)}$ for Table $1 \mathrm{a}$ is not equal to that for Table $1 \mathrm{~b}$.

Therefore it would not be appropriate to use the test statistic $\mathrm{W}^{(\lambda)}$ for measuring and comparing the degree of non-uniformity of odds ratios in several tables and the users should use the measure $\hat{\Psi}^{(\lambda)}$.

\section{CONCLUSION}

For the $\mathrm{I} \times \mathrm{J} \times \mathrm{K}$ contingency table, denote the three variables by $\mathrm{X}, \mathrm{Y}$ and $\mathrm{Z}$. The NOTFI model indicates 
Am. J. Biostatistics 1 (1): 17-22, 2010

\begin{tabular}{|c|c|c|c|c|}
\hline \multirow[b]{2}{*}{ Z } & \multirow[b]{2}{*}{$\mathrm{X}$} & \multicolumn{3}{|l|}{$\mathrm{Y}$} \\
\hline & & (1) & (2) & (3) \\
\hline \multicolumn{5}{|c|}{ (a) $n=207$} \\
\hline \multirow[t]{3}{*}{ (1) } & (1) & 5 & 4 & 5 \\
\hline & (2) & 5 & 8 & 4 \\
\hline & (3) & 4 & 8 & 5 \\
\hline \multirow[t]{3}{*}{ (2) } & (1) & 9 & 3 & 6 \\
\hline & (2) & 6 & 6 & 3 \\
\hline & (3) & 3 & 6 & 9 \\
\hline \multirow[t]{3}{*}{ (3) } & (1) & 6 & 4 & 3 \\
\hline & (2) & 4 & 3 & 6 \\
\hline & (3) & 3 & 6 & 4 \\
\hline \multirow[t]{3}{*}{ (4) } & (1) & 10 & 8 & 5 \\
\hline & (2) & 8 & 5 & 10 \\
\hline & (3) & 5 & 10 & 8 \\
\hline \multicolumn{5}{|c|}{ (b) $n=1035$} \\
\hline \multirow[t]{3}{*}{ (1) } & (1) & 25 & 20 & 25 \\
\hline & (2) & 25 & 40 & 20 \\
\hline & (3) & 20 & 40 & 25 \\
\hline \multirow[t]{3}{*}{ (2) } & (1) & 45 & 15 & 30 \\
\hline & (2) & 30 & 30 & 15 \\
\hline & (3) & 15 & 30 & 45 \\
\hline \multirow[t]{3}{*}{ (3) } & (1) & 30 & 20 & 15 \\
\hline & (2) & 20 & 15 & 30 \\
\hline & (3) & 15 & 30 & 20 \\
\hline \multirow[t]{4}{*}{ (4) } & (1) & 50 & 40 & 25 \\
\hline & (2) & 40 & 25 & 50 \\
\hline & (3) & 25 & 50 & 40 \\
\hline & \multicolumn{4}{|c|}{$\mathrm{j}$} \\
\hline $\mathrm{t}$ & $\mathrm{i}$ & & & 2 \\
\hline \multicolumn{5}{|c|}{ (c) Values of $\left\{\theta_{\mathrm{ij}(\mathrm{t})}\right\}$ for Tables $6 \mathrm{a}$ and $6 \mathrm{~b}$} \\
\hline \multirow[t]{2}{*}{1} & 1 & & & 0.40 \\
\hline & 2 & & & 1.25 \\
\hline \multirow[t]{2}{*}{2} & 1 & & & 0.25 \\
\hline & 2 & & & 3.00 \\
\hline \multirow[t]{2}{*}{3} & 1 & & & 2.67 \\
\hline & 2 & & & 0.33 \\
\hline \multirow[t]{2}{*}{4} & 1 & & & 3.20 \\
\hline & 2 & & & 0.40 \\
\hline
\end{tabular}

that (1) each of (I-1)(J-1) odds ratios between $\mathrm{X}$ and $\mathrm{Y}$ is uniform among $Z$, (2) each of (I-1)(K-1) odds ratios between $\mathrm{X}$ and $\mathrm{Z}$ is uniform among $\mathrm{Y}$ and (3) each of $(\mathrm{J}-1)(\mathrm{K}-1)$ odds ratios between $\mathrm{Y}$ and $\mathrm{Z}$ is uniform among X. The measure $\Psi^{(\lambda)}$ proposed in this study is useful for measuring and comparing the three kinds of degrees of departure from the NOTFI model; namely, (1) what degree the odds ratios between $\mathrm{X}$ and $\mathrm{Y}$ are apart from the uniformity among $Z$, (2) what degree the odds ratios between $X$ and $Z$ are apart from the uniformity among $\mathrm{Y}$ and (3) what degree the odds ratios between $\mathrm{Y}$ and $\mathrm{Z}$ are apart from the uniformity among $\mathrm{X}$.
Table 7: Values of $\hat{\Psi}^{(\lambda)}$ applied to Table $6 \mathrm{a}$ and $6 \mathrm{~b}$

\begin{tabular}{lll}
\hline Values of $\lambda$ & For Table 6a & For Table 6b \\
\hline-0.4 & 0.134 & 0.134 \\
0 & 0.163 & 0.163 \\
0.6 & 0.162 & 0.162 \\
1.0 & 0.147 & 0.147 \\
1.6 & 0.118 & 0.118 \\
\hline
\end{tabular}

Table 8: Values of power-divergence statistic $\mathrm{W}^{(\lambda)}$ (with 12 degrees of freedom) for testing goodness-of-fit of the NOTFI model, applied to Tables $6 \mathrm{a}$ and $6 \mathrm{~b}$

\begin{tabular}{lll}
\hline Values of $\lambda$ & For Table 6a & For Table $6 \mathrm{~b}$ \\
\hline-0.4 & 8.586 & 42.930 \\
0 & 8.499 & 42.495 \\
0.6 & 8.421 & 42.105 \\
1.0 & 8.401 & 42.005 \\
1.6 & 8.417 & 42.085 \\
\hline
\end{tabular}

From Example 1, we have seen using the proposed measure $\hat{\Psi}^{(\lambda)}$ that for the data in Table 1, the degree of departure from the uniformity of odds ratios (association) between the dumping severity and hospital among the operations is somewhat greater than the degree of departure from the uniformity of odds ratios (association) between the dumping severity and operation among the hospitals. In addition, from Examples 1 and 2, we have seen that the degree of departure from the uniformity of odds ratios (association) between the dose of tolazamide and the tumor among the animals for the data in Table 3 is greater than the degree of departure from the uniformity of odds ratios (association) for the data in Table 1.

The measure $\hat{\Psi}^{(\lambda)}$ would be useful for comparing the degrees of departure from the NOTFI model in several tables. Consider the artificial data in Table 6a and $6 \mathrm{~b}$. All values of observed frequencies in Table $6 \mathrm{a}$ multiplied by 5 equal the values in Table $6 \mathrm{~b}$. Thus, it is natural that the estimated odds-ratios between variables $\mathrm{X}$ and $\mathrm{Y}$ at each level of $\mathrm{Z}$ for Table $6 \mathrm{~b}$ are equal to those for Table $6 \mathrm{a}$ (Table $6 \mathrm{c}$ ). Therefore, the value of $\hat{\Psi}^{(\lambda)}$ (for every $\lambda$ ) for Table 6a is identical with that for Table $6 \mathrm{~b}$ (Table 7). However the value of $\mathrm{W}^{(\lambda)}$ is greater for Table $6 \mathrm{~b}$ than for Table $6 \mathrm{a}$ (Table 8). Therefore the measure $\hat{\Psi}^{(\lambda)}$ rather than test statistic $\mathrm{W}^{(\lambda)}$ would be useful for comparing the degrees of departure from the NOTFI model in several tables.

The readers may be interested in which value of $\lambda$ is preferred for a given table. However, in comparing tables, it seems difficult to discuss this. For example, consider the artificial data in Table 9a and 9b. We see from Table 9c that the value of $\hat{\Psi}^{(0)}$ is greater for Table 
9a than for Table $9 b$, but the value of $\hat{\Psi}^{(1)}$ is less for Table 9a than for Table 9b. So, for these cases, it may be impossible to decide (by using $\hat{\Psi}^{(\lambda)}$ ) whether the degree of departure from the NOTFI model is greater for Table 9a or for Table 9b. But generally, for the comparison between two tables, it would be possible to draw a conclusion if $\hat{\Psi}^{(\lambda)}$ (for every $\lambda$ ) is always greater (or always less) for one table than for the other table. Thus, it seems to be important that the analyst calculates the value of $\hat{\Psi}^{(\lambda)}$ for various values of $\lambda$ and discusses the degree of departure from the NOTFI model in terms of $\hat{\Psi}^{(\lambda)}$ values.

The measure $\hat{\Psi}^{(\lambda)}$ would be useful when one wants to measure how far the odds-ratios $\left\{\theta_{\mathrm{ij}(\mathrm{t})}\right\}$ are directly distant from the uniformity, although $\mathrm{W}^{(\lambda)} / \mathrm{n}$ may be useful when one wants to see how far the estimated cell probability distribution with the structure of NOTFI is distant from the sample cell probability distribution.

Table 9: (a), (b) Artificial data ( $\mathrm{n}$ is sample size) and (c) corresponding values of $\hat{\Psi}^{(\lambda)}$ applied to Tables $9 a$ and $9 b$

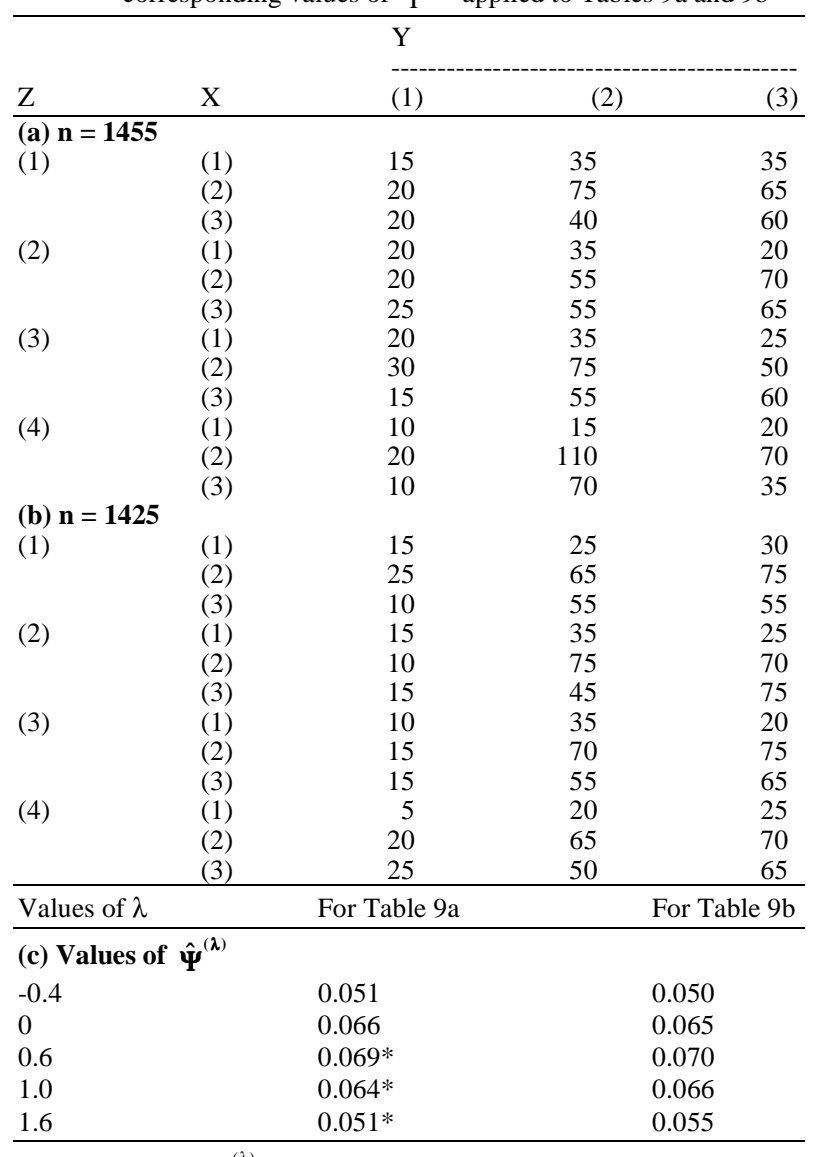

*: Indicates that $\hat{\Psi}^{(\lambda)}$ is less for Table 9 a than for Table $9 \mathrm{~b}$

\section{REFERENCES}

Agresti, A., 1984. Analysis of Ordinal Categorical Data. Wiley, New York, ISBN: 978-0-471-89055-3, pp: 304.

Bishop, Y.M.M., S.E. Fienberg and P.W. Holland, 1975. Discrete Multivariate Analysis: Theory and Practice. The MIT Press, Cambridge, Massachusetts, ISBN: 978-0-387-72805-6, pp: 486.

Cressie, N.A.C. and T.R.C. Read, 1984. Multinomial goodness-of-fit tests. J. R. Stat. Soc. Ser. B., 46: 440-464. http://www.jstor.org/pss/2345686

Grizzle, J.E., C.F. Starmer and G.G. Koch, 1969. Analysis of categorical data by linear models. Biometrics, 25: 489-504. http://www.jstor.org/pss/2528901

Patil, G.P. and C. Taillie, 1982. Diversity as a concept and its measurement. J. Am. Stat. Assoc., 77: 548-561. http://www.jstor.org/pss/2287709

Read, T.R.C. and N.A.C. Cressie, 1988. Goodness-ofFit Statistics for Discrete Multivariate Data. Springer, New York, ISBN: 978-0-387-96682-3, pp: 211.

Tomizawa, S., 1992. More parsimonious linear-bylinear association model in the analysis of crossclassifications having ordered categories. Biometr. J., 34: 129-140. DOI: 10.1002/bimj.4710340202

Tomizawa, S., 1993. A measure of departure from no three-factor interaction model in a $2 \times 2 \times \mathrm{K}$ contingency table. J. Stat. Res., 27: 1-8. http://www.isrt.ac.bd/node/525

Yamamoto, K., Y. Ban and S. Tomizawa, 2008. Generalized measure of departure from no threefactor interaction model for $2 \times 2 \times \mathrm{K}$ contingency tables. Entropy, 10: 776-785. DOI: 10.3390/e10040776

Yanagawa, T., 1986. Analysis of Discrete Multivariate Data (in Japanese). The Kyoritsu Press, Tokyo, ISBN: 978-4-320-01388-9, pp: 112. 